\title{
Patent on gene fragment sends researchers a mixed message...
}

[WASHINGTON] The award of the first US patent for expressed sequence tags (ESTs) short sequences of DNA commonly used as tools to decode longer sequences - has led to speculation that similar rights might soon be granted to gene fragments whose patents have been pending for years.

The patent was awarded in October to Incyte Pharmaceuticals, Inc. of Palo Alto, California. But some in the biotechnology community say the award may not be relevant to most EST patent applications. Indeed, there is some doubt as to whether the Patent and Trademark Office even considered Incyte's inventions to be ESTs.

The controversy over ESTs began in the early 1990s when Craig Venter, then a researcher with the National Institutes of Health (NIH), and subsequently the founder of the Institute for Genomic Research, pioneered their use as a shortcut to sequencing the human genome.

At first, the NIH applied for patents on ESTs. But after much political turmoil, it began to oppose proprietary rights to gene fragments, and raised its concern last year at the news that the patent office was likely to grant such patents (see Nature 386, 312; 1997). Meanwhile, however, private companies flooded the office with applications covering millions of ESTs.

The patent granted to Incyte is for one full-length gene, as well as polynucleotides

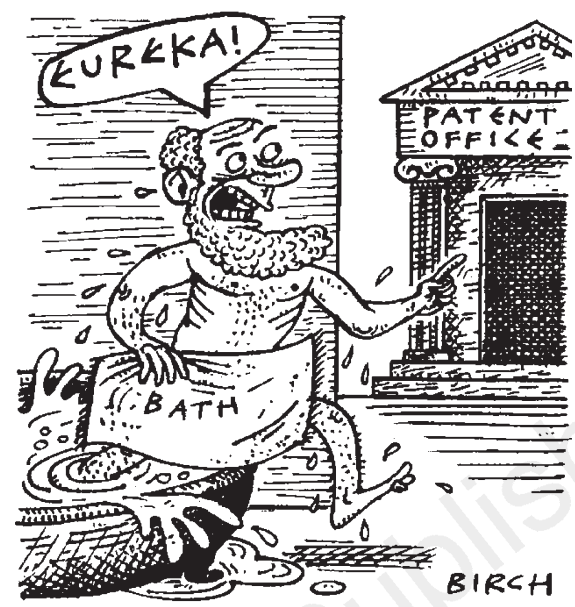

that encode more than 40 protein kinases. Lee Bendekgey, the company's vice president for legal affairs, says this was not the company's first application for an EST patent, but it "breezed through relatively easily".

The reason, he believes, was the fulllength gene, and that the fragments were highly characterized. In early debates about EST patenting, Bendekgey says, they were stereotyped as being almost random DNA sequences about which little was known.

That may still be true for many of the 1.2 million ESTs for which Incyte has filed patent applications, but Bendekgey and others say it no longer holds for other fragments with better known functions.

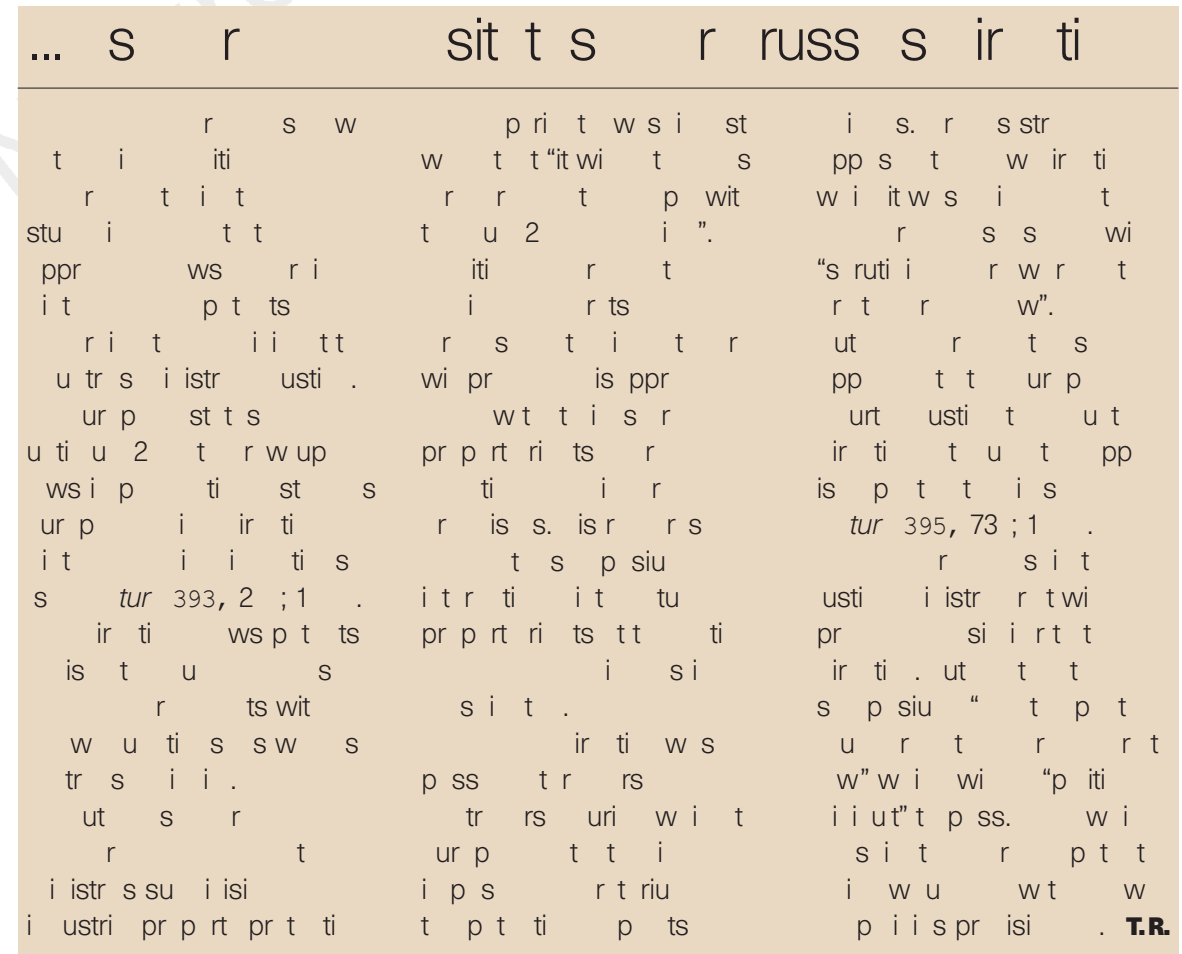

Dave Schmickel, a patent counsel with the Biotechnology Industry Organization, says the term EST has become somewhat vague: "An EST is in the eye of the beholder". This is why, according to Patent Office spokesperson Brigid Quinn, some people would even debate whether Incyte's invention "was in fact an EST".

Bendekgey says the office expressed its displeasure when the company issued a press release in November touting the award as the first patent for an EST.

Schmickel and others say that more important than terminology in predicting the success of EST patent applications is whether a company tries to claim broader rights than are warranted by its knowledge of the fragment's structure and function.

Draft guidelines for biotechnology patents, published by the patent office in the summer, say there should be a "correspondence between what the applicant has described ... and what the applicant is claiming".

That may already rule out what some biotechnology researchers fear — that the owner of an EST, even one whose function is unknown, would automatically gain patent rights to larger fragments or whole genes containing that EST that are discovered later.

Any patented invention must pass several tests; for example, it must have a known function, must be novel and non-obvious (meaning that not anyone can work it out based on the current state of the art), and be adequately described. Claiming rights to a gene of unknown function, based on a subset of the whole gene, would not appear to pass these tests.

Not all the fears have been eased, however. At a meeting on intellectual property rights at the National Academy of Sciences in Washington last week, Francis Collins, head of the NIH's National Human Genome Research Institute, called the Incyte patent award a "disturbing turn of events" and feared that it signalled the patent office's willingness to grant overly broad proprietary rights.

But Jack Tribble, a patent lawyer with Merck and Co., predicted at the same meeting that EST patents will not preclude a patent on the parent gene being granted to someone else, unless perhaps the gene contains a large number of proprietary ESTs, a matter that may have to be resolved in the courts.

He and others also predict that only a fraction of the millions of EST patent applications on file will be granted. Companies and universities will lack the time and money to pursue - and defend - patents on all but their top-priority gene fragments. Tony Reichhardt 